\title{
Topraksız tarımda domates yetiştiriciliğinde bitki gelişme parametreleri ile sıcaklık ve ıșık arasındaki ilişkilerin modellenmesi
}

\section{Modelling of the effect of light and temperature on the development parameters of tomatoes in the soilless cultures}

\author{
Melek ÖZKAPLAN@, Ahmet BALKAYA® \\ Ondokuz Mayıs Üniversitesi, Ziraat Fakültesi, Bahçe Bitkileri Bölümü, Samsun \\ Sorumlu yazar (Corresponding author): M. Özkaplan, e-posta (e-mail): melek.ozkaplan@omu.edu.tr \\ Yazar(lar) e-posta (Author e-mail): abalkaya@omu.edu.tr
}

\section{MAKALE BILGISII}

Alınış tarihi 10 Şubat 2020

Düzeltilme tarihi 05 Mart 2020

Kabul tarihi 05 Mart 2020

\section{Anahtar Kelimeler:}

Domates

Işık

Sicaklık

Topraksız tarım

Modelleme

\begin{abstract}
ÖZ
Calıșmada, Hindistan cevizi lifi ve kayayünü substratlarında yetiștirilen salkım domateste gelișme Çalışmada, Hindistan cevizi lifi ve kayayünü substratlarında yetiştirilen salkım domateste gelişme
parametreleri üzerine, sıcaklık ve ışığın kantitatif etkileri incelenmiştir. Araştırma, 2014-2015 yıllarında ü̧ farklı dikim döneminde, gölgeli ve gölgesiz koşullar altında cam serada yürütülmüştür. Bitkisel materya olarak Bandita $F_{1}$ salkım domates çeşidi kullanılmıştır. Bitki gelişme parametreleri bakımından; dikimden çiçeklenmeye kadar geçen gün sayısı, bitki boylanma hızı, bitki yapraklanma hızı, gövde çapı artıș hızı ve meyve büyüme periyodu özellikleri incelenmiştir. Bu parametrelerden elde edilen veriler, çoklu regresyon analizleri ile matematiksel modellere dönüştürülmüştür. Oluşturulan modeller yardımıyla, bitki gelişme unsurları için Slide Write Plus paket programında 3 boyutlu grafikler çizilmiştir. Araştırmada, Hindistan cevizi lifi ve kayayünü substratlarında yetiștirilen domates bitkilerinde, bitki gelișme unsurlarının 16.42 $26.22^{\circ} \mathrm{C}$ sıcaklık ve $96.10-455.93 \mu \mathrm{mol} \mathrm{s}^{-1} \mathrm{~m}^{-2}$ 1şı belirlenmiştir. Çoklu regresyon analiz sonuçlarına göre elde edilen tahmini değerler ile gerçek bitki gelişme parametreleri arasında istatistiksel olarak önemli düzeyde bir ilişkinin olduğu saptanmıştır. İncelenen bitki gelișme unsurları için üretilen modellerin regresyon katsayılarının $\left(\mathrm{R}^{2}\right), 0.90-0.99$ arasında olduğu tespit edilmistir. Calışma sonucunda; yetistirme ortamı olarak Hindistan cevizi lifi substratının domateste ilk çiçeklenme süresini ve meyve büyüme periyodunda erkenciliği olumlu yönde etkilediği bulunmuştur. Ayrıca domateste her iki topraksız yetiştirme ortamında bitki yapraklanma hızı ve bitki gövde çapı artı hızının, artan 1şık şiddeti ve artan sıcaklık ile doğrusal olarak artış gösterdiği belirlenmiştir. Çalışmada, Hindistan cevizi lifi substratlarında yetistirilen domateste meyve büyüme periyodu modeli; $\mathrm{MBP}=184.8317-8.65659 \times \mathrm{xT}-0.05637 \mathrm{xL}+0.170203 \mathrm{xT}^{2}\left(\mathrm{~s}_{\mathrm{c} a k l 1 \mathrm{k}}{ }^{\circ} \mathrm{C}\right)$ ve $\left(1\right.$ ş1 $\left.\mathrm{k}, \mu \mathrm{mol} \mathrm{s}{ }^{-1} \mathrm{~m}^{-2}\right)\left(\mathrm{R}^{2}: 0.99^{* * *}\right)$ olarak tespit edilmiştir. Kontrollü ortamda yapılan domates üretiminde; farklı sıcaklık ve işık koşullarının bitki gelişmesi üzerine olan etkilerini açıklayan söz konusu bu matematiksel modeller kullanılarak, optimum bitki yönetimi sağlanabilecektir.
\end{abstract}

\section{ARTICLE INFO}

Received 10 February 2020

Received in revised form 05 March 2020 Accepted 05 March 2020

\section{Keywords:}

Tomato

Light

Temperature

Soilless culture

Modelling

\section{ABSTRACT}

In this study, the effects of temperature and light on development parameters have been examined for cluster tomatoes grown on cocopeat and rockwool substrates. This research carried out in three planting periods in 2014-2015 in the shaded/unshaded glasshouse. Bandita $F_{1}$ was used. Plant development parameters such as days from planting to blooming, plant height increase rate, leaf appearance increase rate, stem diameter increase rate and fruit growth period have been analyzed. The obtained data were transformed into mathematical models with multi regression analyses. The defined models used to draw 3D graph with Slide Write Plus package program for plant development parameters. It has been determined plant development parameters for the tomatoes grown on substrates of cocopeat and rockwool vary changed between $16.42-26.22^{\circ} \mathrm{C}$ for the temperature and $96.10-455.93 \mu \mathrm{mol} \mathrm{s}^{-1} \mathrm{~m}^{-2}$ for the light intensity. It has been found that there is a statistically significant relationship between predicted parameters based on multi-regression analysis and actual parameters. Regression coefficients of the designed models for examined plant development parameters have been between 0.90-0.99. Research has found that cocopeat substrate has positive effect on blooming process and tomatoes fruit growth period. It has been found that increasing light and temperature has linear relationship to the rate of plant leaf appearance rate and stem diameter increase. Fruit growth period model for cocopeat substrate was found as $\mathrm{MBP}=184.8317-$ 8.65659xT-0.05637xL $+0.170203 \mathrm{xT}^{2}$ (temperature, ${ }^{\circ} \mathrm{C}$ ), (light, $\left.\mu \mathrm{mol} \mathrm{s}^{-1} \mathrm{~m}^{-2}\right)\left(\mathrm{R}^{2}: 0.99 * * *\right)$. Using these mathematical models for the tomato production in a controlled environment optimum plant management can be achieved since these will help better understand plant development parameters under different temperature and light conditions. 


\section{Giriş}

Bitkisel üretimde tohumun çimlenme ve çıkışından itibaren, bitkinin olgunluğuna kadar geçen süreçteki fizyolojik ve morfolojik değişimler, bitki gelişimi olarak tanımlanmaktadır. Bitki gelişme süreci, kantitatif bir olgudur. Büyüme ve farklılaşma olmak üzere iki bilimsel temele dayanmaktadır. Bitki gelişme hızı ise bitkinin bu süreç içerisinde geçirdiği safhaların süresinin matematiksel olarak hesaplanması ile belirlenmektedir (Uzun 1996). Bu süreci etkileyen çevresel ve bünyesel faktörler vardır (Eriş 2007). Bitki gelişimi ve bu faktörler arasındaki etkileşimin tam ve doğru anlaşılabilmesinde kantitatif çalışmalar oldukça önemlidir. Özellikle, örtüaltı sebze yetiştiriciliğinde çevresel faktörlerin bitki büyüme ve gelişme süreçlerinin tamamında düzenli olarak kontrolü ile yetiştiricilik sonucunda istenilen optimum büyüme, gelişme ve yüksek verim değerleri sağlanabilmektedir. Kontrollü yetiştiricilik koşulları altında, bitki kalite ve kantitesinin iyileştirilmesi ve yetiştiricilik uygulamalarının kolaylaştırılması amacıyla bitki gelişme performansı ve iklim faktörleri arasındaki ilişkilerin tespit edilmesi ve bu süreci özetleyen matematiksel modellerin üretilmesi oldukça önemlidir (Uzun 1996). Bunun için örtüaltı sebze yetiştiriciliğinde, öncelikle iklimsel parametreler ile yetiştirilecek bitki arasındaki ilişkilerin optimize edilmesi gereklidir (Özkaplan 2018).

Son yıllarda ülkemizde geleneksel sera işletmelerinin yanı sıra, iklim kontrollü modern sera işletmelerinin sayıları hızla artmaktadır (Kandemir ve Uzun 2019). Özellikle yetiştiricilik için gerekli olan iklim faktörleri ve bitki besin elementlerinin anlık olarak kontrol edilebildiği, yönlendirilebildiği topraksız tarım sera işletmeleri, üstün ürün kalitesi ve yüksek verim değerleri nedeniyle ülkemizde ticari yetiştiricilikte oldukça fazla yaygınlaşmıştır (Özkaplan ve Balkaya 2019). Bugün ülkemizde topraksız tarım alanı, 13134 dekara ulaşmıştır (ÖKS 2019). Jeotermal suların ısıtma amaciyla sera üretiminde kullanımı, ülkemizde topraksız tarım ile sebze yetiştiriciliğini yıl boyunca olanaklı hale getirmekte, bunun sonucunda üreticiler sebze yetiştiriciliğinde daha düşük maliyetler ile kaliteli ve yüksek verime, tüketiciler ise her mevsim kaliteli ürüne ulaşabilmektedir. Türkiye'de topraksız tarım tekniğiyle yetiştirilen ve ekonomik değeri en yüksek olan sebze türü domatestir. Domates yetiştiriciliğinde bitki büyüme ve gelişimine doğrudan etki eden iki önemli iklim faktörü ise sıcaklık ve 1şıtır. Bu iki parametrenin birlikte yada tek başına etkileri, büyüme ve gelişme sürecinde meydana gelen fizyolojik ve metabolik olayların optimum düzeylerde gerçekleşmesinde aktif rol oynamaktadır. Işık, bitki üzerinde fotosentez başta olmak üzere bitki fizyolojisi ve bitki gelişimi gibi birçok süreçte etkili olan en önemli unsurdur (Odabaş ve ark. 2010). Ayrıca bu süreçleri kontrol eden ve olumlu yönde yönlendiren bir etkiye sahiptir (Andiç 1993). Domates yetiştiriciliğinde bitki gelişme periyodunu etkileyen önemli diğer bir çevre faktörü ise sıcaklık parametresidir (Tüzel ve Gül 2008). Özellikle meyve büyüme periyodunu etkileyen ana değişken sicaklık unsurudur (De Koning 2000).

Genel olarak üretim planlamasında, yetiştirilecek tür ve çeşit seçimi yapılırken bölgenin maksimum ve minimum sıcaklık değerlerinin analiz edilmesi ile özellikle bitkilerin uygun yetiştirme zamanı, çiçeklenme periyodu ve ne zaman hasada geleceği gibi unsurlar önceden tahmin edilebilmektedir (Yoldaş ve Eşiyok 2005). Bu nedenle, sebze yetiştiriciliğinde önemli bir paya sahip olan domateste, bitki gelişme unsurları üzerine değişen ortam sıcaklıkları ve 1şık şiddetinin etkisini ortaya koyan matematiksel modeller geliştirilmiştir (El-Gizawy ve ark. 1992; Uzun 1996; Uzun 2006; Özkaplan 2018). Model, genel olarak sistemin değişen koşullar altındaki davranışlarının analiz edilmesi, kontrol edilmesi ve geleceği hakkında varsayımlarda bulunulmasının matematiksel terimler ile ifade edilmesidir (Özden 2015). Matematiksel modeller, pratikte gerçek bir nesneyi oluşturmadan önce teoride oluşturulan sistemin anlaşılmasına, tasarlanmasına, çalışmasına ve kontrolüne yardımcı olmaktadır (Özkaplan 2019). Ülkemizde son yıllarda birçok bitki türünde bitki büyüme ve gelişme parametrelerini tahmin etmek amacıyla farklı sıcaklık ve 1 şık şiddetinin etkisi incelenerek birçok matematiksel model geliştirilmiştir (Uzun 2001; Cemek 2002; Odabaş 2003; Balkaya 2004; Cengiz 2017; Özkaplan 2018). Ancak büyüme ve gelişmeyi yönlendiren sıcaklık ve 1şı değerleri, her bir bitki türü için farklılık gösterdiği gibi her bir yetiştirme periyodu ve yetiştirme tekniği için de değişkenlik göstermektedir. Bu çalışmada, topraksız tarım koşullarında serada yetiştirilen Bandita $F_{1}$ salkım domates çeşidinin gelişme parametreleri üzerine sıcaklık ve ışığın kantitatif etkilerinin ayrıntılı olarak belirlenmesi ve matematiksel olarak modellenmesi amaçlanmıştır.

\section{Materyal ve Yöntem}

$\mathrm{Bu}$ araştırma, Ondokuz Mayıs Üniversitesi Ziraat Fakültesine ait cam serada yürütülmüş̧ür. Çalışmada, topraksız tarım salkım domates üretiminde yaygın olarak yetiştirilen Bandita $F_{1}$ çeşidi kullanılmıştır. Cam serada mevcut 1 şık ve sıcaklık değerlerinde varyasyon oluşturulması amacıyla, gölgeleme etkisi $\% 55$, enerji tasarrufu $\% 58$ oranında olan ve 1şık geçirgenliği \%45 olan akrilik, alüminyum, yüksek yoğunluklu polietilen dokuma özelliğine sahip gölgeleme ve enerji perdesi kullanılmıştır (Özkaplan 2018).

Çalışmada, Hindistan cevizi lifi $(100 \times 20 \times 16 \mathrm{~cm})$ ve kayayünü yetiştirme torbalarının $(100 \times 20 \times 7.5 \mathrm{~cm})$, her birine 3 adet domates fidesi dikilmiştir. Domates fidesi dikimleri, üç farklı dönemde (2014 y1l ilkbahar döneminde 03.04.2014 tarihinde; 2014 y1lı sonbahar yetiştiriciliğinde 29.08.2014 tarihinde ve 2015 y1lı ilkbahar döneminde ise 05.03.2015 tarihinde) gerçekleştirilmiştir.

Her bir yetiştirme periyodunda, Hindistan cevizi lifi ve kayayünü yetiştirme substratlarına dikilen domates fideleri hem \%100 doğal 1şık altında hem de gölgeleme materyali altında olacak şekilde iki farklı ekolojik çevrede yetiştirilmiştir. Çalışmada, kullanılan besin eriyiği, domates bitkilerinin ihtiyaç duyduğu besin maddelerinin sulama suyuna ilave edilmesiyle, komple besin eriyiği şeklinde modifiye edilmiş "Hoagland besin çözeltisi" kullanılarak sağlanmıştır (Özkaplan 2018). Bitkilere besin çözeltisi uygulamadan önce, hazırlanan çözeltilerin tümünde $\mathrm{pH}$ ve EC ölçümleri yapılmıştır. Uygulanan nitrik asit ilavesi ile besin çözeltisi $\mathrm{pH}$ değerinin (6.0-6.5) ve EC değerinin (2.0-2.5 ds m-1) domates yetiştiriciliği için uygun sınırlar içinde kalması sağlanmıştır. Çalışmada, bilgisayar yardımı ile programlanabilen onset hobo datalogger ve quantum par sensörleri ile yetiştirme dönemlerine ait saatlik verilerden ortalama sera içi ortam sıcaklığı ve fotosentetik aktif radyasyon değerleri hesaplanmıştır (Uzun 1996; Özkaplan 2018). Çalışmada, incelenen üç farklı yetiştirme dönemine ait elde edilen ortalama sıcaklık ve 1şı değerleri Çizelge 1'de verilmiştir.

Kantitatif analizler için, ilk ölçümlerde dikim günü fide boyu, fide yaprak sayısı ve fide gövde çapı değerleri tespit edilmiştir. İkinci ölçümler ise vejetasyon periyodunun sonunda 
Çizelge 1. Farklı yetiştirme dönemlerine ait ortalama sıcaklık ve ışık değerleri.

Table 1. Average temperature and light observations for different growing periods.

\begin{tabular}{|c|c|c|c|c|c|c|}
\hline \multirow{2}{*}{ Ortam } & \multicolumn{2}{|c|}{2014 yılı ilkbahar } & \multicolumn{2}{|c|}{2014 yll sonbahar } & \multicolumn{2}{|c|}{2015 yılı ilkbahar } \\
\hline & Işık $\left(\mu \mathrm{mol} \mathrm{s}{ }^{-1} \mathrm{~m}^{-2}\right)$ & Sicaklık ( $\left.{ }^{\circ} \mathrm{C}\right)$ & Işık $\left(\mu \mathrm{mol} \mathrm{s}{ }^{-1} \mathrm{~m}^{-2}\right)$ & Sicaklık ( $\left.{ }^{\circ} \mathrm{C}\right)$ & Işık $\left(\mu \mathrm{mol} \mathrm{s}{ }^{-1} \mathrm{~m}^{-2}\right)$ & Sicaklık ( $\left.{ }^{\circ} \mathrm{C}\right)$ \\
\hline HCL & 455.93 & 26.22 & 223.46 & 18.14 & 432.67 & 24.60 \\
\hline HCL (\%50 Gölgeli) & 264.54 & 23.96 & 96.1 & 16.42 & 182.31 & 22.71 \\
\hline KY & 455.93 & 26.22 & 223.46 & 18.14 & 432.67 & 24.60 \\
\hline KY (\%50 Gölgeli) & 264.54 & 23.96 & 96.1 & 16.42 & 182.31 & 22.71 \\
\hline
\end{tabular}

HCL: Hindistan cevizi lifi, KY: Kayayünü.

HCL: Cocopeat, KY: Rockwool.

her bir uygulama için ayrı ayrı olacak şekilde yapılmıştır. Çalışmada, domates fidelerinin dikiminden ilk çiçekler görülünceye kadar geçen süre, her bir uygulama için ilk çiçeklenme tarihi olarak belirlenmiştir (Demirsoy 2016). Araştırmada bitki boylarında meydana gelen artışın, geçen zamana oranı ile bitki boylanma hızları (Demir ve ark. 2001), bitki gövde çapında meydana gelen artışın, geçen süreye oranı ile bitki gövde çapı artış hızları (Eriş 2007) ve bitki yapraklarındaki sayıca artışın, geçen süreye oranı ile bitki yapraklanma hızları saptanmıştır (Uzun 1996). Her bir ortam için ilk çiçeklenme tarihinden ilk hasat tarihine kadar geçen süre ise meyve büyüme periyodu olarak hesaplanmıştır (Uzun 1996).

Deneme, faktöriyel deneme desenine göre her bir uygulamada 3 tekerrürlü olacak şekilde kurulmuştur. İki farklı substrat içinde elde edilen sayısal verilerin değerlendirilmesinde çoklu regresyon analizleri, Microsoft Office Excel programında yapılmış, regresyon katsayıları $\left(\mathrm{R}^{2}\right)$, standart hataları $(\mathrm{SH})$ hesaplanmış (*: $\mathrm{p}<0.05, * *: \mathrm{p}<0.01, * * *: \mathrm{p}<0.001)$ ve elde edilen modeller, Slide Write Plus paket programında 3 boyutlu olarak grafiklere dönüştürülmüştür.

\section{Bulgular ve Tartışma}

\subsection{Dikimden ilk çiçeklenmeye kadar geçen süre (DÇKGS)}

Domates bitkilerinde ilk çiçek taslakları görülünceye kadar geçen süre, erkencilik ve verimi etkileyen önemli bir bitki gelişme parametresidir (Atherton ve Haris 1986; Uzun ve Demir 1996). Çalışmada, Hindistan cevizi lifi ve kayayünü ortamları için farklı sıcaklık $\left(\mathrm{T},{ }^{\circ} \mathrm{C}\right)$ ve 1 şı $\left(\mathrm{L}, \mu \mathrm{mol} \mathrm{s}{ }^{-1} \mathrm{~m}^{-2}\right)$ değerlerinde, dikimden ilk çiçeklenmeye kadar geçen sürenin tahmin edilebilmesi için üretilen matematiksel modellerin (Eşitlik 1 ve Eşitlik 2) regresyon katsayıları sırasıyla, $\mathrm{R}^{2}: 0.90$ ve $\mathrm{R}^{2}: 0.92$ olarak belirlenmiştir.

$$
\mathrm{DÇKGS}=22.48175-0.000024 \times \mathrm{T}^{2} \times L
$$

$$
\mathrm{SH}=(0.36708) * * *(1.99 \mathrm{E}-06) * * * \mathrm{R}^{2}=0.90 * * *
$$$$
\text { DÇKGS }=24.26519-0.000022 \times \mathrm{T}^{2} \times \mathrm{L}
$$

$$
\mathrm{SH}=(0.29294) * * *(1.59 \mathrm{E}-06) * * * \mathrm{R}^{2}=0.92 * * *
$$

Her iki yetiştirme ortamında da en erken çiçeklenme süresi için optimum sıcaklık ve 1şık isteği değerleri sırasıyla $26.22^{\circ} \mathrm{C}$ ve $455.93 \mu \mathrm{mol} \mathrm{s}{ }^{-1} \mathrm{~m}^{-2}$ olarak tespit edilmiştir. En erken ilk çiçeklenme ise dikimden 14 gün sonra Hindistan cevizi lifi substratlarında yetiştirilen domates bitkilerinde belirlenmiştir. Optimum 1şı, sıcaklık değerleri ve birbirleriyle olan aktivasyonu, fotosentezin 1 şı reaksiyonlarında üretilen enerji ile sıcaklığa bağlı karbon reaksiyonlarındaki enzim aktiviteleri arasında denge oluşturmaktadır. Bu sayede bitki fotosentez hızında artışlar meydana getirmekte ve yüksek oranda asimilat üretmektedir (Taiz ve Zeiger 2008). Çalışmada, fotosentez hızının artması asimilat oluşumuna katkı sağlamış ve sonucunda çiçek oluşumunu hızlandırmış olabilir. Bu nedenle araştırmada yüksek sıcaklık koşullarında, artan 1şık şiddetinin etkisi ile dikimden çiçeklenmeye kadar geçen gün sayısı doğrusal olarak azalış göstermiştir (Şekil 1). Yüksek 1şık şiddeti koşullarında; sıcaklık değerlerinin artmasıyla birlikte dikimden çiçeklenmeye kadar geçen süre eğrisel olarak azalmıştır. Düşük 1 şık

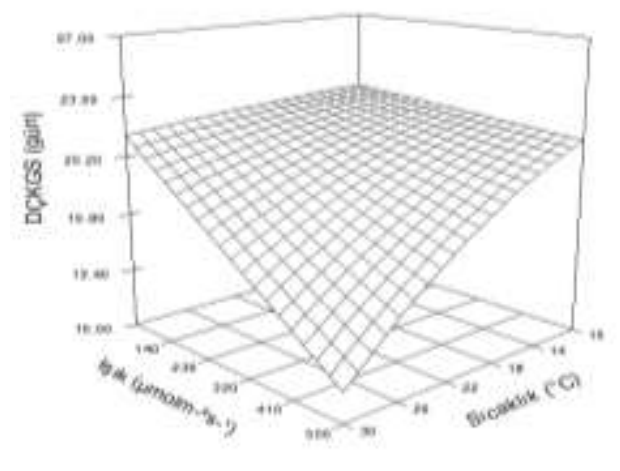

(a)

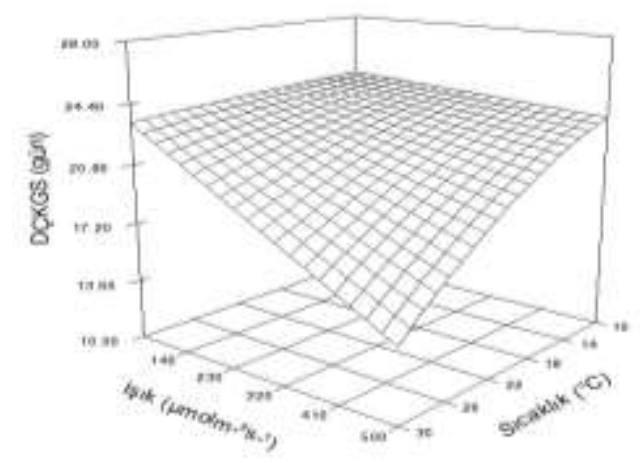

(b)

Şekil 1. Hindistan cevizi lifi (a) ve kayayünü (b) ortamlarında yetiştirilen domateste, sıcaklık $\left({ }^{\circ} \mathrm{C}\right)$ ve 1 şık şiddetine $\left(\mu \mathrm{mol} \mathrm{s} \mathrm{s}^{-1} \mathrm{~m}^{-2}\right)$ bağlı olarak dikimden çiçeklenmeye kadar geçen gün sayısının (d) değişimleri.

Figure 1. Variance of the days from planting to the blooming (d) based on temperature (o $\mathrm{C}$ ) and light intensity $\left(\mu \mathrm{mol} \mathrm{s} \mathrm{s}^{-1} \mathrm{~m}^{-2}\right)$ for the tomatoes grown on (a) cocopeat and (b) rockwool substrates. 
koşullarında ise artan sıcaklık değerlerinin dikimden çiçeklenmeye kadar geçen gün sayısı üzerine etkisinin çok daha az olduğu ve çiçeklenmenin daha geç sürelerde gerçekleştiği tespit edilmiştir (Şekil 1). Bu dönemde; yüksek sicaklık değerlerinin de etkisiyle bitkilerde vejetatif büyüme artmış ve dikimden çiçeklenmeye kadar geçen süre gecikmiştir. Bu durumda artan sıcaklık koşullarının bitki karbon reaksiyonları, enzim aktivitelerini olumlu etkilemesine karşın, düşük 1 şık koşullarındaki yetersiz enerji üretimine bağlı olarak bitki yeterli karbonhidrat üretimini gerçekleştirememiş olabilir. Benzer sonuçlar, domates yetiştiriciliğinde sıcaklık ve ışı koşullarının etkilerinin incelendiği çalışmalar ile de ortaya konulmuştur (Dileman ve Heuvelink 1992; Uzun 1996; Y1ldiz 2013; Özkaplan 2018). Bazı araştırıcılar, sıcaklığın bitkilerde çiçek gözü oluşumu üzerinde önemli etkisinin olduğunu ve artan sıcaklık değerlerinin de ilk çiçek taslağı oluşumu için geçen süreyi kısalttığını bildirmişlerdir (Uzun 1997; Atherton ve Haris 1986; De Koning 1994; Kandemir 2005; Özkaplan 2018).

\subsection{Bitki boylanma hızı (BBH)}

Çalışmada, bitki boylanma hızının tahmin edilebilmesi için üretilen matematiksel modellerde (Eşitlik 3 ve Eşitlik 4) Hindistan cevizi lifi ve kayayünü ortamları için tespit edilen regresyon katsayıları sırasıyla, $\mathrm{R}^{2}$ : 0.96 ve $\mathrm{R}^{2}$ : 0.97 olduğu saptanmıştır. Regresyon analizi sonucunda, sıcaklık ve 1şı̆̆ın bitki boylanma hızı üzerine etkisinin istatistiksel olarak önemli düzeyde olduğu belirlenmiştir.

$\mathrm{BBH}=-0.604+0.144 \times \mathrm{T}+0.005 \times \mathrm{xL}-0.00026 \times \mathrm{T} \times \mathrm{L} \quad$ (Eşitlik 3)

$$
\begin{aligned}
& \mathrm{SH}=(0.165417)^{* *}(0.008008) * * *(0.000862) * * * \\
& (3.44 \mathrm{E}-05)^{* * *} \mathrm{R}^{2}=0.96^{* * *}
\end{aligned}
$$

$\mathrm{BBH}=-0.6625+0.1335 \times \mathrm{T}+0.00627 \times \mathrm{L}-0.0003 \times \mathrm{T} \times \mathrm{L}$ (Eşitlik 4)

$$
\begin{aligned}
& \mathrm{SH}=(0.131745)^{* * *}(0.006378)^{* * *}(0.000687)^{* * *} \\
& (2.74 \mathrm{E}-05)^{* * *} \mathrm{R}^{2}=0.97 * * *
\end{aligned}
$$

Çalı̧̧mada, en yüksek bitki boylanma hızı, ortalama 2.49 $\mathrm{cm}$ gün ${ }^{-1}$ ile yüksek sıcaklık $\left(23.96^{\circ} \mathrm{C}\right)$ ve düşük 1 şı $(264.54$ $\mu \mathrm{mol} \mathrm{s} \mathrm{m}^{-1}$ ) koşullarında Hindistan cevizi lifi substratlarında bulunmuştur. Yüksek sıcaklık koşullarında, 1şı şiddetinin azalan etkisi sonucunda bitkide gibberellik asit seviyesi artmış olabilir. Bu durumun bitki boylanma hızını arttırdığı ve buna bağlı olarak boğum aralarının uzadığı saptanmıştır. Çalışmada, sicaklığın yüksek olduğu koşullarda, farklı 1şık şiddeti değerlerinde yetiştirilen domateste, 1şık yoğunluğu arttıkça bitki boylanma hızının azalış gösterdiği ve boğum arası uzunluklarının kısaldığı tespit edilmiştir (Şekil 2). Bu durumda 1şık ve sıcaklık arasındaki dengenin sağlandığı, üretilen asimilatların daha fazla depolandığı dolayısıyla bitkinin daha dolgun ve pişkin olduğu söylenebilir. Cockshull ve ark. (1992) ve Uzun (1997), domates bitkisinde sıcaklığın bitki boylanma hızı üzerine pozitif yönde doğrusal bir etkisinin olduğunu bildirmişlerdir. Odabaş ve Gülümser (2005) yaptıkları çalışmada, artan 1 şı şiddetinin etkisiyle bitki gövdesinde fotosentetik pigment miktarının arttığı gövde uzamasının nispeten yavaşladığını, yüksek ışık koşullarında gövde boyunun daha kısa kaldığını belirtmiş̧lerdir. Araştırma sonuçları, daha önce yürütülen bu çalışmaları destekler nitelikte olmuştur.

\subsection{Bitki gövde çapı artış hızı (BGÇAH)}

Domates yetiştiriciliğinde farklı sıcaklık ve 1 şı değerlerinde, bitki gövde çapı artış hızının tahmin edilebilmesi için üretilen denklemlerde tespit edilen regresyon katsayıları Hindistan cevizi lifi için $\mathrm{R}^{2}$ : 0.95 (Eşitlik 5) ve kayayünü ortamı için ise $\mathrm{R}^{2}$ : 0.93 (Eşitlik 6) olarak bulunmuştur.

$$
\mathrm{BGÇAH}=0.0297+0.00012 \times \mathrm{L}+0.0000352 \mathrm{xT}^{2}
$$

$$
\mathrm{SH}=(0.004485) * * *(1.75 \mathrm{E}-05) * * *(1.52 \mathrm{E}-05) *
$$
$\mathrm{R}^{2}=0.95 * * *$

$$
\mathrm{BGÇAH}=0.0175+0.0000877 \mathrm{xL}+0.0000627 \mathrm{xT}^{2}
$$

(Eşitlik 6)

$$
\begin{aligned}
& \mathrm{SH}=(0.004961) * * *(1.93 \mathrm{E}-05) * * *(1.68 \mathrm{E}-05) * * \\
& \mathrm{R}^{2}=0.93 * * *
\end{aligned}
$$

Araştırma sonucunda, $16.42^{\circ} \mathrm{C}$ ile $26.22^{\circ} \mathrm{C}$ aralığındaki tüm sıcaklık değerlerinde, 1şı̆̆ın $96.10 \mu \mathrm{mol} \mathrm{s}^{-1} \mathrm{~m}^{-2} \mathrm{den} \quad 455.93$ $\mu \mathrm{mol} \mathrm{s} \mathrm{m}^{-2}$ ye artmasıyla birlikte domateste gövde çap1 artış hızının doğrusal olarak artış gösterdiği belirlenmiştir (Şekil 3). $\mathrm{Bu}$ durumda artan 1 şı koşullarında yetiştirilen domates bitkilerinde, fotosentetik üretim arttığından bitkide kuru madde birikimi söz konusu olmuştur. Araştırma sonucunda elde edilen

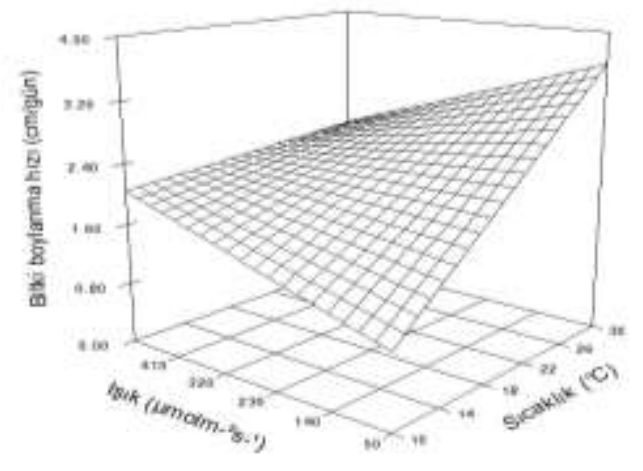

(a)

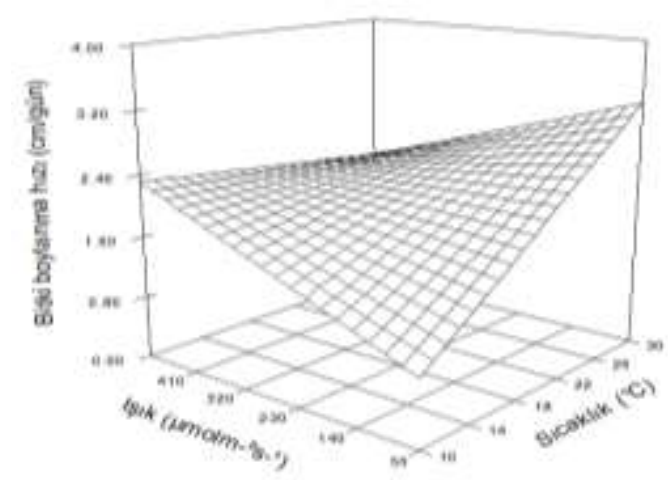

(b)

Şekil 2. Hindistan cevizi lifi (a) ve kayayünü (b) ortamlarında yetiştirilen domates bitkilerinin sıcaklık $\left({ }^{\circ} \mathrm{C}\right)$ ve 1 şık şiddetine $\left(\mu \mathrm{mol} \mathrm{s}{ }^{-1} \mathrm{~m}^{-2}\right)$ bağlı olarak bitki boylanma hızının ( $\mathrm{cm}$ gün $\left.^{-1}\right)$ değişimleri.

Figure 2. Variance of the rate of plant height increase $\left(\mathrm{cm} \mathrm{d}^{-1}\right)$ based on temperature $\left({ }^{\circ} \mathrm{C}\right)$ and light intensity $\left(\mu \mathrm{mol} \mathrm{s}^{-1} \mathrm{~m}^{-2}\right)$ for the tomatoes grown on (a) cocopeat and (b) rockwool substrates. 


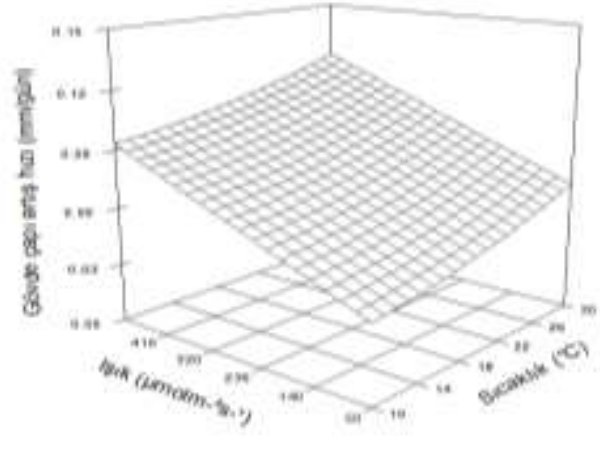

(a)

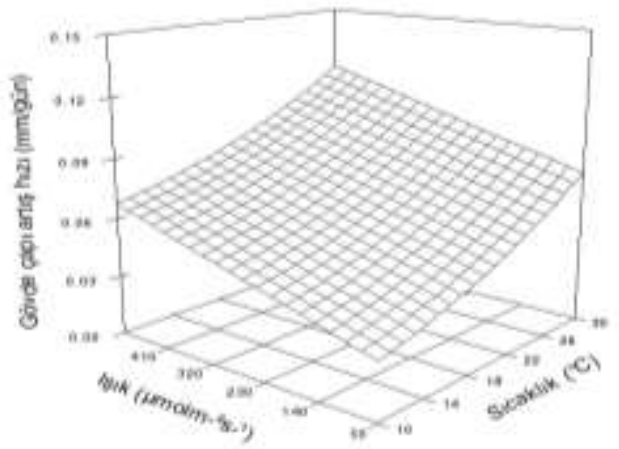

(b)

Şekil 3. Domateste sıcaklık $\left({ }^{\circ} \mathrm{C}\right)$ ve 1 şık şiddetine $\left(\mu \mathrm{mol} \mathrm{s}{ }^{-1} \mathrm{~m}^{-2}\right)$ bağlı olarak Hindistan cevizi lifi (a) ve kayayünü (b) ortamlarında bitki gövde çapı artış hızının ( $\left.\mathrm{mm}_{\text {gün }}{ }^{-1}\right)$ değişimleri.

Figure 3. Variance of the rate of stem diameter $\left(\mathrm{mm} \mathrm{d}^{-1}\right)$ based on temperature $(\stackrel{\circ}{ } \mathrm{C})$ and light intensity $\left(\mu \mathrm{mol} \mathrm{s} \mathrm{s}^{-1} \mathrm{~m}^{-2}\right)$ for the tomatoes grown on $(\mathrm{a})$ cocopeat and (b) rockwool substrates.

bulgulara göre, uygulamalar arasında $0.112 \mathrm{~mm} \mathrm{gün}^{-1}$ ile en yüksek bitki gövde çapı artış hızının ortalama $26.22^{\circ} \mathrm{C}$ sıcaklık ve $455.93 \mu \mathrm{mol} \mathrm{s}^{-1} \mathrm{~m}^{-2}$ 1şı1k şiddeti koşullarında; en düşük bitki gövde çapı artış hızının ise $0.037 \mathrm{~mm}_{\text {gün }}{ }^{-1}$ ile $16.42^{\circ} \mathrm{C}$ sıcaklık ve $96.10 \mu \mathrm{mol} \mathrm{s}^{-1} \mathrm{~m}^{-2}$ 1şı şiddeti koşullarında olduğu bulunmuştur. Cemek (2002) sıcaklığın artması ile bitki gövde çapının arttığını; Odabaş ve Gülümser (2005) ise artan 1şık şiddetinin bitki gövde çapını arttırdığını belirtmişlerdir. Ayrıca Brazaitytė ve Kasiulevičiūtė (2013) ve Demirsoy (2016) yaptıkları çalışmalarda domates bitkilerine uygulanan ek 1şıklandırmanın, bitki gövde çapını artırdığını bildirmişlerdir.

\subsection{Bitki yapraklanma hızı (BYH)}

Araştırmada, domates yetiştiriciliğinde bitki yapraklanma hızı ile sıcaklık ve 1şık değerleri ilişkilendirilmiştir. Bu ilişkininin tahmin edilebilmesi amaciyla yapilan regresyon analizi sonucunda, üretilen matematiksel modellerde (Eşitlik 7 ve Eşitlik 8) Hindistan cevizi lifi ve kayayünü ortamları için tespit edilen regresyon katsayılarının sirasıyla, $R^{2}: 0.96$ ve $R^{2}: 0.97$ olduğu saptanmıştır.

\section{$\mathrm{BYH}=0.129775+0.007102 \times \mathrm{T}+0.000126 \times \mathrm{L} \quad($ Eşitlik 7)}

$$
\begin{aligned}
& \mathrm{SH}=(0.012817) * * *(0.00078) * * *(2.13 \mathrm{E}-05) * * * \\
& \mathrm{R}^{2}=0.97 * * *
\end{aligned}
$$

$\mathrm{BYH}=0.085331+0.008079 \mathrm{xT}+0.000148 \mathrm{xL}$

(Eşitlik 8)

$$
\begin{aligned}
& \mathrm{SH}=(0.018604) * * *(0.001132) * * *(3.08 \mathrm{E}-05) * * * \\
& \mathrm{R}^{2}=0.96 * * *
\end{aligned}
$$

Araştırma sonucunda; tüm sıcaklık değerlerinde, artan 1 şık şiddetinin etkisiyle birlikte domateste bitki yapraklanma hızının doğrusal olarak artış gösterdiği belirlenmiştir (Şekil 4). Yüksek 1ş1k şiddetinde yetiştirilen domates bitkilerinde, bitki yapraklanma hızı artışının düşük 1 şı koşullarında yetiştirilenlere göre daha fazla olduğu tespit edilmiştir. Çalışmada, en yüksek bitki yapraklanma hızı; ortalama 0.37 adet gün ${ }^{-1}$ ile $455.93 \mu \mathrm{mol} \mathrm{s}^{-1} \mathrm{~m}^{-2}$ 1şı ve $26.22^{\circ} \mathrm{C}$ sicaklık değerlerinde belirlenmiştir. En düşük bitki yapraklanma hızı ise ortalama 0.22 adet gün ${ }^{-1}$ ile düşük sıcaklık ve düşük $1 s ̧ 1 k$ $\left(16.42^{\circ} \mathrm{C}, 96.10 \mu \mathrm{mol} \mathrm{s}{ }^{-1} \mathrm{~m}^{-2}\right)$ koşullarından elde edilmiştir. Picken ve ark. (1986), yaz aylarında yaprak çıkış oranının kış aylarına oranla daha yüksek olduğunu, bunun en önemli nedeninin ise yüksek 1 şık şiddeti olduğunu bildirmişlerdir. Ayrıca Dileman ve Heuvelink (1992), domateste artan 1şı şiddetinin etkisiyle bitki yapraklanma hızının arttığını ve benzer şekilde Uzun ve Demir (1996) ise artan sıcaklık değeriyle birlikte yaprak çıkış oranının artış gösterdiğini belirtmişlerdir. Uzun (1996), domateste yüksek 1ş1k şiddetinin yaprak çıkış oranını arttırdığını ve düşük 1 şık şiddetinin ise azalttığını bildirmiştir. Bu çalışmada da benzer sonuçlar elde edilmiştir.

\subsection{Meyve büyüme periyodu (MBP)}

Araştırmada farklı sıcaklık ve 1şık değerlerinde, ürün olgunlaşma zamanının tahmin edilebilmesi için üretilen denklemlerde (Eşitlik 9 ve Eşitlik 10) tespit edilen regresyon katsayıları, Hindistan cevizi lifi için $\mathrm{R}^{2}$ : 0.99 ve kayayünü ortamı için ise $\mathrm{R}^{2}$ : 0.97 olarak bulunmuştur.

$$
\mathrm{MBP}=184.8317-8.65659 \times \mathrm{x}-0.05637 \mathrm{xL}+0.170203 \mathrm{xT}^{2}
$$

$$
\begin{aligned}
& \mathrm{SH}=(16.90465) * * *(1.65814)^{* * *}(0.004627) * * * \\
& (0.040785)^{* * *} \mathrm{R}^{2}=0.99 * * *
\end{aligned}
$$

$$
\mathrm{MBP}=186.3285-8.34352 \times \mathrm{x}-0.05035 \mathrm{xL}+0.163065 \mathrm{xT}^{2}
$$

$\mathrm{SH}=(29.12684)^{* * *}(2.856987) *(0.007972) * * *$ $(0.070273) * \mathrm{R}^{2}=0.97 * * *$

Şekil 5 incelendiğinde domateste her iki substrat için, meyve büyüme periyodunun artan 1şı şiddeti ile doğrusal, artan sıcaklıkla eğrisel bir azalış gösterdiği tespit edilmiştir. Uygulamalar arasında, domates meyvelerinin en hizlı olgunlaşma süreci yüksek ışı ve yüksek sıcaklık koşullarında elde edilmiştir. Çalışmada; ortalama $26.22^{\circ} \mathrm{C}$ sıcaklık ve 455.93 $\mu \mathrm{mol} \mathrm{s}{ }^{-1} \mathrm{~m}^{-2} 1$ şı $\mathrm{k}$ şiddeti koşullarında, Hindistan cevizi lifi substratlarında domates meyveleri ortalama 48 gün, kayayünü substratlarında ise 55 günde meyve hasat olgunluğuna gelmiştir. Pearson (1992), 1şık şiddeti ile domateste meyve gelişimi arasında doğrusal bir ilişkinin olduğunu ve $18^{\circ} \mathrm{C}^{\prime}$ de $6 \mathrm{MJ} \mathrm{s}^{-1} \mathrm{~m}^{-2}$ 1şık şiddetinde 75 günde hasat olgunluğuna geldiğini bildirmiştir. Uzun (1996), domates yetiştiriciliğinde meyvelerin ilk hasat olgunluğuna ortalama $11.1^{\circ} \mathrm{C}$ sicaklık ve $3.08 \mathrm{MJ} \mathrm{s}$ ${ }^{1} \mathrm{~m}^{-2} 1$ şık şiddetinde; 96 gün sürede ve ortalama $24.9^{\circ} \mathrm{C}$ sicaklık ve $6.24 \mathrm{MJ} \mathrm{s} \mathrm{s}^{-1} \mathrm{~m}^{-2}$ 1ş1 


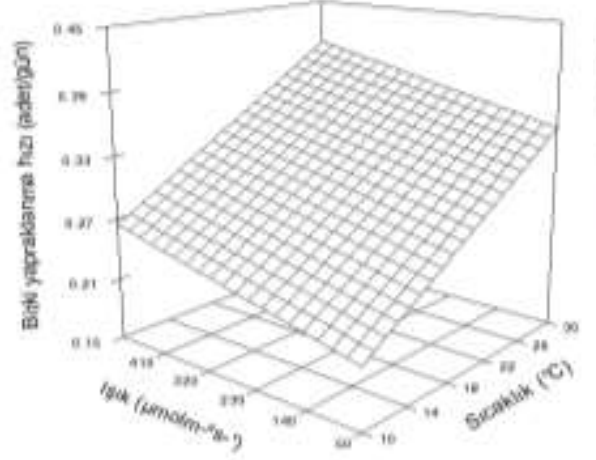

(a)

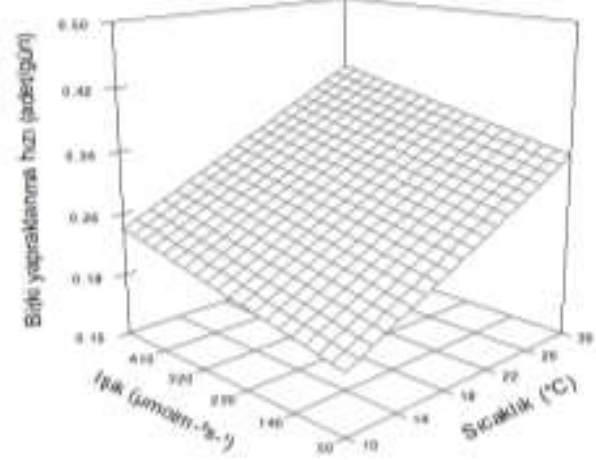

(b)

Şekil 4. Hindistan cevizi lifi (a) ve kayayünü (b) ortamlarında yetiştirilen domateste, sıcaklık $\left({ }^{\circ} \mathrm{C}\right)$ ve 1 şık şiddetine $\left(\mu \mathrm{mol} \mathrm{s}{ }^{-1} \mathrm{~m}^{-2}\right)$ bağlı olarak bitki yapraklanma hızının (adet gün $\left.{ }^{-1}\right)$ değişimleri.

Figure 4. Variance of the leaf appearance rate $\left(p e r \mathrm{~d}^{-1}\right)$ based on temperature (o $\mathrm{C}$ ) and light intensity $\left(\mu \mathrm{mol} \mathrm{s} \mathrm{s}^{-1} \mathrm{~m}^{-2}\right)$, for the tomatoes grown on (a) cocopeat and (b) rockwool substrates.

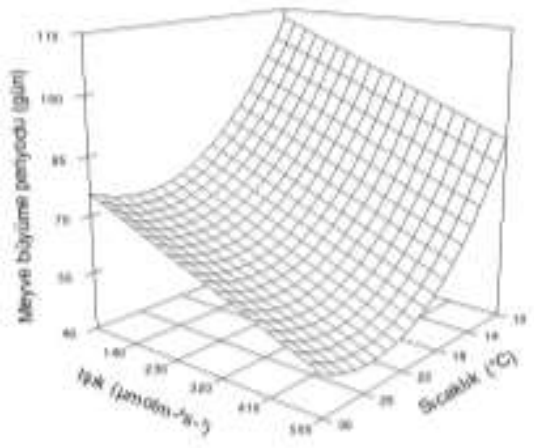

(a)

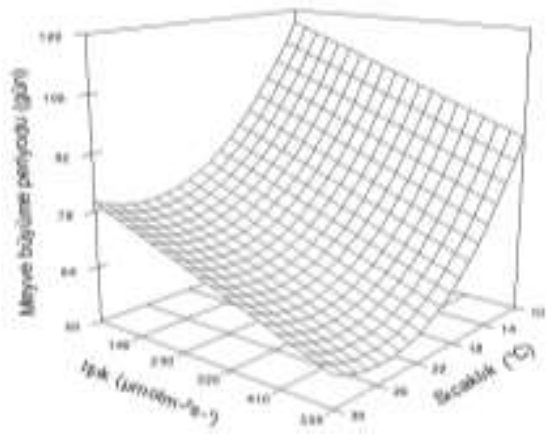

(b)

Şekil 5. Hindistan cevizi lifi (a) ve kayayünü (b) ortamlarında yetiştirilen domateste, sıcaklık $\left({ }^{\circ} \mathrm{C}\right)$ ve 1 şık şiddetine $\left(\mu \mathrm{mol} \mathrm{s} \mathrm{s}^{-1} \mathrm{~m}^{-2}\right)$ bağlı olarak meyve büyüme periyodu gün sayısının değişimleri.

Figure 5. Variance of the fruit growth period (number of days) (d) based on temperature (으) and light intensity ( $\mu \mathrm{mol} \mathrm{s}^{-1} \mathrm{~m}^{-2}$ ), for the tomatoes grown on (a) cocopeat and (b) rockwool substrates.

meyvelerin hasat edildiğini belirlemiştir. De Koning (2000) ise domates yetiştiriciliğinde olgunlaşma süresinin ortalama $17^{\circ} \mathrm{C}$ 'de 73 gün ve ortalama $26^{\circ} \mathrm{C}$ 'de ise 42 günde gerçekleştiğini tespit etmiştir. Araştırıcı, sıcaklık değerlerinin meyve gelişim periyodunu etkileyen en önemli parametre olduğunu bildirmiştir. Adams ve ark. (2001), domateste büyüme ve gelişme üzerine sıcaklığın etkilerini inceledikleri bir çalışmada, domates bitkilerin ortalama $14^{\circ} \mathrm{C}, 18^{\circ} \mathrm{C}, 22^{\circ} \mathrm{C}$ ve $26^{\circ} \mathrm{C}$ 'de yetiştirmişler ve sirasıyla meyvelerin hasat olgunluğuna 95 gün, 65 gün, 46 gün ve 42 günde ulaştığını bildirmişlerdir. Ülkemizde yapılan bir çalışmada, sonbahar döneminde yetiştirilen domateslerde ilk hasada kadar geçen süre 69 gün ile 114 gün arasında; ilkbahar yetiştirme döneminde ise ilk 67 gün ile 74 gün arasında değişim gösterdiği belirlenmiştir (Tüzel ve ark. 2009).

\section{Sonuç}

Tarımda kullanılan matematiksel modeller yardımıyla oluşturulan simülasyonlar ile optimum koşullar kolaylıkla test edilebilmekte ve pratikte uygulanabilmektedir. Son yıllarda tarım sektöründe bitki büyüme, gelişme ve verim sürecinin takip edilmesinde ve tarımsal üretimde mevcut kaynakların etkin ve sürdürülebilir kullanılması amacıyla matematiksel modellerin kullanımı yaygınlaşmaya başlamıştır. Ayrıca farklı sıcaklık ve 1şı koşullarındaki bazı bitki gelişme safhalarını/süreçlerini tahmin edebilen modeller yardımıyla farklı bölgeler için uygun çevre koşulları oluşturulması mümkün olabilmektedir.

Büyüme ve gelişmenin üretim sezonu boyunca devam ettiği domates gibi bitkilerde, bitki gelişmesi ve meyve oluşumu arasındaki dengenin yetiştiricilik periyodu boyunca korunması büyük önem taşımaktadır. Çalışmada, 96.1-455.93 $\mu \mathrm{mol} \mathrm{s}^{-1} \mathrm{~m}^{-2}$ aralığında $1 s ̧ 1 \mathrm{k}$ ve $16-26^{\circ} \mathrm{C}$ aralığında sıcaklık referans değerleri içerisinde genel olarak artan sicaklık ve 1şık şiddeti domates bitkilerinde, bitki boylanma hızı hariç ilk çiçeklenmeye kadar geçen süre, gövde çapı artış hızı, bitki yapraklanma hızını ve meyve büyüme periyodunu pozitif yönde etkilediği saptanmıştır. $\mathrm{Bu}$ çalışma sonucunda üretilen regresyon modelleri yardımıyla; topraksız tarımda domates yetiştiriciliğinde, optimum sicaklık ve 1 şı değerlerinin sağlanması koșuluyla oluşturulacak üretim planlaması sonucunda, istenilen bitki büyüme ve gelişme hedeflerine istenilen zamanda ulaşılabilecektir. Böylece topraksız tarımda Hindistan cevizi lifi ve kayayünü substratları kullanılarak yüksek, ekonomik verim ve üstün meyve kalitesi sağlanabilecektir. 


\section{Teşekkür}

$\mathrm{Bu}$ çalışma; doktora tezinin bir bölümünü içermektedir. Ondokuz Mayıs Üniversitesi Bilimsel Araştırma Fonu (PYO.ZRT.1904.13.024) tarafindan desteklenmiştir.

\section{Kaynaklar}

Adams SR, Cockshull KE, Cave CRJ (2001) Effect of temperature on the growth and development of tomato fruits. Annals of Botany 88: 869-877.

Andiç C (1993) Tarımsal Ekoloji. Atatürk Üniversitesi Ziraat Fakültesi Ders Notları. Yayın No: 106, Erzurum.

Atherton JG, Harris GP (1986) Flowering. In: Atherton JG, Rudich J (Eds), The Tomato Crop. A Scientific Basis for Improvement, London, England, pp: 167-200.

Balkaya A (2004) Modelling the effect of temperature on the germination speed in some legume crops. Journal of Agronomy 3: 179-183.

Brazaitytė A, Kasiulevičiūtė A (2013) The comparison of supplemental blue and green light effects on two cucumber hybrid transplant grown under HPS lighting in greenhouse. The Sixth International Scientific Conference Proceedings, Lithuanian Research Centre for Agriculture and Forestry 2(6): 49-53.

Cemek B (2002) Farklı sera örtü malzemelerinin bitki büyüme, gelişme, verim ve sera içi çevre koşullarına etkisi. Doktora Tezi, Ondokuz Mayıs Üniversitesi Fen Bilimleri Enstitüsü, Samsun.

Cengiz E (2017) Bazı kabak anaçlarında tohumların çimlenmesi ve çıkışı üzerine sıcaklığın etkisinin modellenmesi. Yüksek Lisans Tezi, Ondokuz Mayıs Üniversitesi Fen Bilimleri Enstitüsü, Samsun.

Cockshull KE, Graves CJ, Carol RJ (1992) The influence of shading on yield of glasshouse tomatoes. Journal of Horticultural Science 67(1): 11-24.

De Koning AdNM (1994) Development and dry matter distrubution in glasshouse tomato quantitive aproach. PhD Thesis, Wageningen Agricultural University, Wageningen.

De Koning AdNM (2000) The effect of temperature, fruit load and salinity on development rate of tomato fruit. Acta Horticulturae 519: 85-94.

Demir Y, Uzun S, Cemek B (2001) Sonbahar turfandacılığında 1sıtmasız seralarda farklı torba kültürlerinde ortam sıcaklığ 1 ile bitki büyüme, gelişme ve verim ilişkileri. 6. Ulusal Seracılık Sempozyumu, Muğla.

Demirsoy M (2016) Sera koşullarında farklı yapay 1 şı, renk ve kaynaklarının (Lycopersicon esculentum Mill.), biber (Capsicum annuum L.) ve patlicanda (Solanum melongena L.) fide büyüme, gelişme, kalite ve dikim sonrası adaptasyonlarına etkilerinin kantitatif yöntemlerle incelenmesi. Doktora Tezi, Ondokuz Mayıs Üniversitesi Fen Bilimleri Enstitüsü, Samsun.

Dileman JA, Heuvelink E (1992) Factors affecting the number of leaves preceding the first inflorescence in tomato. Journal of Horticultural Science 67(1): 1-10.

El-Gizawy AM, Abdallah MMF, Gomaa HM, Mohamed SS (1992) Effect of different shading levels on tomato plants. 2. Yield and Fruit Quality Acta Horticultural 323: 349-354.

Eriş A (2007) Bahçe Bitkileri Fizyolojisi. VI. Baskı, Uludağ Üniversitesi Ziraat Fakültesi Ders Notları, Bursa.

Kandemir D (2005) Sera şartlarında sıcaklık ve 1şı̆̆ın biberde (Capsicum annuum L.) büyüme, gelişme ve verim üzerine kantitatif etkileri. Doktora Tezi, Ondokuz Mayıs Üniversitesi Fen Bilimleri Enstitüsü, Samsun.

Kandemir D, Uzun S (2019) Farklı ışık ve sıcaklık şartlarının sera biber yetiştiriciliğinde büyüme parametreleri üzerine kantitatif etkilerinin modellenmesi. Ondokuz Mayıs Üniversitesi Anadolu Tarım Bilimleri Dergisi 34(1): 1-11.
Odabaş MS (2003) Sıcaklık ve 1şı̆̆ın baklada (Vicia faba L.) büyüme, gelişme ve verime kantitatif etkileri. Doktora Tezi, Ondokuz Mayıs Üniversitesi Fen Bilimleri Enstitüsü, Samsun.

Odabaş MS, Gülümser A (2005) Farklı ışık şiddetinin bakla'da (Vicia faba $L$.) verim ve bazı bitkisel özelliklere etkisi. Tarım Bilimleri Dergisi 11(3): 286-291.

Odabaş MS, Camas N, Cirak C, Radušiene J, Janulis V, Ivanauskas L (2010) The quantitative effects of temperature and light intensity on phenolics accumulation in St. John's wort (Hypericum perforatum L). Natural Product Communications 5(4): 535-540.

ÖKS (2019) Örtüaltı Kayıt Sistemi. T.C. Tarım ve Orman Bakanlığı, Ankara. Sözlü Erişim 29 Mayıs 2019.

Özkaplan M (2018) Serada topraksız domates yetiştiriciliğinde büyüme, gelişme ve verim üzerine 1 şık ve sıcaklığın kantitatif etkilerinin modellenmesi. Doktora Tezi, Ondokuz Mayıs Üniversitesi Fen Bilimleri Enstitüsü, Samsun.

Özkaplan M (2019) Tarımda matematiksel model kullanımı. 3. Uluslararası Unidokap Karadeniz Sempozyumu, Tokat, s. 456-461.

Özkaplan M, Balkaya A (2019) Işık ve sıcaklığın topraksız tarım koşullarında salkım domatesin meyve kalitesine etkisi. Ondokuz Mayıs Üniversitesi Anadolu Tarım Bilimleri Dergisi 34(3): 227238.

Özden ÜH (2015) Yöneylem Araştırması http://www.unalozden.com/download/yoneylemaraştirmasiall.pdf. Erişim 19 Mayıs 2019.

Pearson S (1992) Modelling the effect of temperature on the growth and development of horticultural crops. PhD Thesis, The University of Reading, England.

Picken AJF, Stewart K, Klapwicjk K (1986) Germination and vegetative development. In: Atherton JG, Rudich J (Eds), The Tomato Crop. Chapman and Hall, London, English, pp. 167-200.

Taiz L, Zeiger E (2008) Bitki Fizyolojisi. 3. Baskı Çeviri (Ed: Türkan I), Palme Yayıncılık, Ankara.

Tüzel Y, Gül A (2008) Seralarda İyi Tarım Uygulamaları. Bahçe Ürünlerinde Çevre Dostu Uygulamaların Yaygınlaştırılması ve İş Olanağı Yaratılması için Ziraat Mühendislerinin Kapasitelerinin Geliştirilmesine Yönelik Eğitim Projesi. Proje No: TR0205.01/002/02/011, İzmir.

Tüzel Y, Duyar H, Öztekin GB, Gül A (2009) Domates anaçlarının farklı dikim tarihlerinde bitki gelişimi, sıcaklık toplamı isteği, verim ve kaliteye etkileri. Ege Üniversitesi Ziraat Fakültesi Dergisi 46: 79-92.

Uzun S (1996) The quantitative effects of temperature and light environment on the growth, development and yield of tomato and aubergine. PhD Thesis, The University of Reading, England.

Uzun S, Demir Y (1996) Sıcaklık ve ışığın bitki büyüme, gelişme ve verime etkileri (II. Gelişme). Ondokuz Mayıs Üniversitesi Ziraat Fakültesi Dergisi 11:201-212.

Uzun S (1997) Sıcaklık ve 1şı̆̆ın bitki büyüme, gelişme ve verimine etkisi (I.Büyüme). Ondokuz Mayıs Üniversitesi Ziraat Fakültesi Dergisi 12: 147-156.

Uzun S (2001) Serada domates ve patlıcan yetiştiriciliğinde bazı büyüme ve verim parametreleri ile sicaklık ve 1 şı arasındaki ilişkiler. Türkiye 6. Ulusal Seracılık Sempozyumu, Muğla, s. 97102.

Uzun S (2006) The quantitative effects of temperature and light on the number of leaves preceding the first fruiting inflorescence on the stem of tomato (Lycopersicon esculentum Mill.) and aubergine (Solanum melogena L.). Scientia Horticulturae 109: 142-146.

Yıldız D (2013) Gölgelemenin sırık domates yetiştiriciliğinde verim, kalite ve bazı argonomik özellikler üzerine etkisi. Yüksek Lisans Tezi, Gaziosmanpaşa Üniversitesi Fen Bilimleri Enstitüsü, Tokat.

Yoldaş F, Eşiyok D (2005) Termal zamanın ( $\left({ }^{\circ} \mathrm{C}-\mathrm{Gün}\right)$ bitkisel üretimde kullanım1. Ege Üniversitesi Ziraat Fakültesi Dergisi 42: 207-218. 